\title{
Genetic Polymorphisms of Pneumocystis jirovecii in HIV-Positive and HIV-Negative Patients in Northern China
}

\author{
TING XUE ${ }^{1 \star}$, WEI-QIN DU ${ }^{2}$, WEN-JUAN DAI ${ }^{1}$, YI-SHAN LI ${ }^{1}$, SHU-FENG WANG ${ }^{3}, J^{\prime}$-LING WANG ${ }^{4}$ \\ and XIN-RI ZHANG ${ }^{1}$ \\ ${ }^{1}$ NHC Key Laboratory of Pneumoconiosis, Key Laboratory of Prophylaxis and Treatment and Basic Research \\ of Respiratory Diseases of Shanxi Province, Department of Respiratory and Critical Care Medicine, \\ First Affiliated Hospital of Shanxi Medical University, Taiyuan, P.R. China \\ ${ }^{2}$ Department of clinical inspection, Eleventh Affiliated Hospital of Shanxi Medical University, Lvliang, P.R. China \\ ${ }^{3}$ Department of Clinical Inspection, First Affiliated Hospital of Shanxi Medical University, Taiyuan, P.R. China \\ ${ }^{4}$ Department of Translation Medicine, Jinzhou Medical University, Jinzhou, P.R. China
}

Submitted 18 September 2021, accepted 15 December 2021, published online 23 February 2022

\begin{abstract}
Pneumocystis jirovecii is an opportunistic fungus that can cause severe and potentially fatal Pneumocystis pneumonia (PCP) in immunodeficient patients. In this study, we investigated the genetic polymorphisms of $P$. jirovecii at eight different loci, including six nuclear genes (ITS, 26S rRNA, sod, dhps, dhfr and $\beta$-Tub) and two mitochondrial genes (mtLSU-rRNA and $c y b$ ) in three PCP cases, including two patients with HIV infection and one without HIV infection in Shanxi Province, P.R. China. The gene targets were amplified by PCR followed by sequencing of plasmid clones. The HIV-negative patient showed a coinfection with two genotypes of P.jirovecii at six of the eight loci sequenced. Of the two HIV-positive patients, one showed a coinfection with two genotypes of $P$. jirovecii at the same two of the six loci as in the HIV-negative patient, while

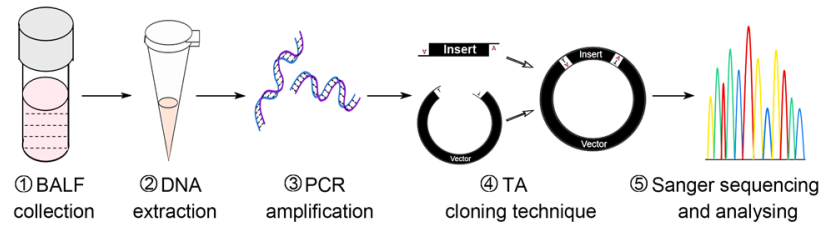

the other showed a single infection at all eight loci sequenced. None of the three drug target genes ( $d h f r$, dhps and $c y b$ ) showed mutations known to be potentially associated with drug resistance. This is the first report of genetic polymorphisms of $P$. jirovecii in PCP patients in Shanxi Province, China. Our findings expand our understanding of the genetic diversity of $P$. jirovecii in China.
\end{abstract}

Ke y w ord s: Pneumocystis jirovecii, genetic polymorphisms, genotypes, multilocus, epidemiology

\section{Introduction}

Pneumocystis is a genus of atypical fungi demonstrating different degrees of genetic diversity between and within different species that infect mammals with high host specificity. The human-specific species, Pneumocystis jirovecii, causes life-threatening Pneumocystis pneumonia (PCP) in immunodeficient individuals, especially those with human immunodeficiency virus (HIV) infection (Ma et al. 2018). Recent studies have indicated a high prevalence of $P$. jirovecii colonization and infection in individuals with chronic obstructive pulmonary disease (COPD) (Wang et al. 2015; Cañas-Arboleda etal. 2019; Xue et al. 2020).
However, the epidemiology and genetic diversity of $P$.jirovecii in different patient populations remain poorly understood.

Although genetic diversity of $P$. jirovecii has been reported in multiple studies from different regions in China (Li et al. 2013; Deng et al. 2014; Sun et al. 2015; Wang et al. 2019), all these studies are limited to only a few loci, and there is no such report from Shanxi Province in Northern China. In this study, we retrospectively investigated three confirmed cases of PCP, including two in HIV-positive patients and one in the HIV-negative patient from our hospital in Shanxi Province. Genetic polymorphisms of $P$. jirovecii in these patients were determined at eight different loci.

\footnotetext{
* Corresponding author: T. Xue, NHC Key Laboratory of Pneumoconiosis, Key Laboratory of Prophylaxis and Treatment and Basic Research of Respiratory Diseases of Shanxi Province, Department of Respiratory and Critical Care Medicine, First Affiliated Hospital of Shanxi Medical University, Taiyuan, P.R. China; e-mail: beyondtinger@126.com.

This work is licensed under the Creative Commons Attribution-NonCommercial-NoDerivatives 4.0 License (https://creativecommons. org/licenses/by-nc-nd/4.0/).
} 


\section{Experimental}

\section{Materials and Methods}

Patients and samples. Three patients with PCP were included in this study, including two positive and one negative for HIV-1. Patients were admitted to the Department of Respiratory and Critical Care Medicine of First Affiliated Hospital of Shanxi Medical University between August 2019 and June 2020. The diagnosis of PCP was confirmed based on clinical manifestations and laboratory tests, including hematology, highresolution computed tomography (HRCT), modified Gomori methenamine silver nitrate staining (GMS) of bronchoalveolar lavage fluid (BALF) samples. The two HIV-positive patients had a confirmed diagnosis of the acquired immune deficiency syndrome (AIDS) but did not receive highly active antiretroviral therapy. Based on the ELISA results, the HIV-negative patient was seronegative for HIV-1 and HIV-2 antibodies.

The Medical Ethics Committee approved this retrospective study of our hospital (2019-K051). In addition, written informed consent was obtained from all three patients.
DNA extraction. The BALF specimens were centrifuged at $350 \mathrm{~g}$ for $15 \mathrm{~min}$, followed by washing the cell pellets with saline solution three times. DNA was extracted from washed cell pellets using the conventional phenol-chloroform extraction method. DNA extracts were quantified using a NanoDrop-UV-Vis spectrophotometer (Thermo Fisher Scientific, USA) and stored at $-80^{\circ} \mathrm{C}$ until use.

DNA amplification, cloning, and sequencing. We amplified eight different loci of the P.jirovecii genome using nested PCR with the Premix-Taq PCR kit (TaKaRa Biotechnology Co., Ltd., Dalian, China) following the manufacturer's instructions. The loci included mitochondrial large-subunit rRNA (mtLSUrRNA), cytochrome b (cyb), nuclear large rRNA subunit (26S), and the complete internal transcribed spacers 1 and 2 (ITS1 and ITS2) along with the 5.8S rRNA of the nuclear rRNA operon (referred to as ITS hereafter), superoxide dismutase ( $(s o d)$, dihydropteroate synthase (dhps), dihydrofolate reductase ( $d h f r)$, and $\beta$-tubulin $(\beta$-Tub). The primers used in this study are listed in Table I. The PCR amplification conditions for $\beta$-Tub and $26 \mathrm{~S}$ were the same as those previously reported

Table I

PCR primers used in this study.

\begin{tabular}{|c|c|c|}
\hline Genes (reference) & Primer names and sequences $\left(5^{\prime}-3^{\prime}\right)$ & $\begin{array}{c}\text { Size of nested PCR } \\
\text { products (bp) }\end{array}$ \\
\hline $\begin{array}{l}\text { ITS } \\
\text { (Lee et al. 1998) }\end{array}$ & $\begin{array}{l}\text { 1724F 5'-AAGTTGATCAAATTTGGTC-3' } \\
\text { ITS2R 5'-CTCGGACGAGGATCCTCGCC-3' } \\
\text { ITS1F 5'-CGTAGGTGAACCTGCGGAAGGATC-3' } \\
\text { ITS2R1 5'-GTTCAGCGGGTGATCCTGCCTG-3' }\end{array}$ & 578 \\
\hline $\begin{array}{l}\text { sod } \\
\text { (Esteves et al. 2010b) }\end{array}$ & $\begin{array}{l}\text { MnSOD_Fw 5'-GGGTTTAATTAGTCTTTTTAGGCAC-3' } \\
\text { MnSOD_Rw 5'-CATGTTCCCACGCATCCTAT-3' } \\
\text { SODF3 5'-AGTCTTTTTAGGCACTTGAACCT-3' } \\
\text { SODR4 5'-TCCAAGAATAACTTTGCCTTGAGT-3' }\end{array}$ & 560 \\
\hline $\begin{array}{l}d h f r \\
\text { (Lane et al. 1997) }\end{array}$ & $\begin{array}{l}\text { FR208 5'-GCAGAAAGTAGGTACATTATTACGAGA-3' } \\
\text { FR1018 5'-AAGCTTGCTTCAAACCTTGTGTAACGCG-3' } \\
\text { FR242 5'-GTTTGGAATAGATTATGTTCATGGTGTACG-3' } \\
\text { FR1038 5'-GCTTCAAACCTTGTGTAACGCG-3' }\end{array}$ & 798 \\
\hline $\begin{array}{l}\text { dhps } \\
\text { (Ma et al. 1999) }\end{array}$ & $\begin{array}{l}\text { DHPS1 5'-CAAATTAGCGTATCGAATGACC-3' } \\
\text { DHPS2 5'-GCAAAATTACAATCAACCAAAGTA-3' } \\
\text { DHPS3 5'-AGCGCCTACACATATTATGG-3' } \\
\text { DHPS4 5'-GTTCTGCAACCTCAGAACG-3' }\end{array}$ & 278 \\
\hline $\begin{array}{l}c y b \\
\text { (Esteves et al. 2010a) }\end{array}$ & $\begin{array}{l}\text { CytbFw 5'-CCCAGAATTCTCGTTTGGTCTATT-3' } \\
\text { CytbRw 5'-AAGAGGTCTAAAAGCAGAACCTCAA-3' } \\
\text { CytbF3 5'-TCTCGTTTGGTCTATTGGTG-3' } \\
\text { CytbR4 5'-AAGCAGAACCTCAAATTCAAGATA-3' }\end{array}$ & 590 \\
\hline $\begin{array}{l}\text { mtLSU rRNA } \\
\text { (Wakefield 1996) }\end{array}$ & $\begin{array}{l}\text { pAZ102_E 5'-GATGGCTGTTTCCAAGCCCA-3' } \\
\text { pAZ102_H 5'-GTGTACGTTGCAAAGTACTC-3' } \\
\text { pAZ102_X 5'-GTGAAATACAAATCGGACTAGG-3' } \\
\text { pAZ102_Y 5'-TCACTTAATATTAATTGGGGACC-3' }\end{array}$ & 252 \\
\hline $\begin{array}{l}\beta \text {-Tub } \\
\text { (Pasic et al. 2020) }\end{array}$ & $\begin{array}{l}\text { Pneumo } \\
\text { Tub_F 5'-TCATTAGGTGGTGGAACGGG-3' } \\
\text { Pneumo } \\
\text { Tub_R 5'-ATCACCATATCCTGGATCCG-3' }\end{array}$ & 303 \\
\hline $\begin{array}{l}\text { 26S rRNA } \\
\text { (Pasic et al. 2020) }\end{array}$ & $\begin{array}{l}\text { PneumoLSU_F 5'-TCAGGTCGAACTGGTGTACG-3' } \\
\text { PneumoLSU_R 5'-TGTTCCAAGCCCACTTCTT-3' }\end{array}$ & 297 \\
\hline
\end{tabular}


(Pasic et al. 2020), and the conditions for other genes were the same as described in previous studies (Lee et al. 1998; Wang et al. 2019; Xue et al. 2019). DNA from $P$. jirovecii-positive specimens stored in our laboratory was used as the positive control. A non-template control with ultrapure-distilled water was included in each PCR run. To prevent cross-contamination of the samples, separate rooms were used, and the PCR mixture from each step of nested PCR was covered with $40 \mu \mathrm{l}$ of sterile liquid paraffin. All PCR products were separated by electrophoresis on $2 \%$ agarose gels, stained with $4 \mathrm{~S}$ Green Plus Nucleic Acid Stain (Sangon Biotech Co., Ltd. Shanghai, China), and visualized under UV irradiation. The amplified DNA bands of the expected sizes were excised from the gel and extracted using an agarose gel DNA extraction kit (Tiangen Biotech Co., Ltd., Beijing, China). Following the manufacturer's instructions, the extracted DNA fragment was cloned into the TA cloning vector pMD18-T (TaKaRa Biotechnology Co., Ltd., Dalian, China). Recombinant plasmid clones were selected by blue-white screening on agar plates containing ampicillin. For each PCR product, 8 to 13 plasmid clones were randomly selected for Sanger sequencing in the ABI 3730xl DNA analyzer (Thermo Fisher Scientific, USA).

Sequence analysis and genotyping. The nucleotide sequences obtained in this study were analyzed and aligned using ClustalW software (https://www.genome. jp/tools-bin/clustalw). At least two plasmid clones are required to define a nucleotide polymorphism. The genotypes were named based on previously published nomenclature (Table II). The reference sequence for each gene was obtained from GenBank, with its accession number listed as follows: ITS, MK300654; $m t L S U$ rRNA, M58605; cyb, AF320344; sod, AF146753; dhfr, AF090368; dhps, AF139132; $\beta$-Tub, MG208106 and 26S KT272445. Known P. jirovecii multi-locus sequence type (MLST) profiles at $\beta$-Tub, $c y b, 26 S$, and sod genes were retrieved from the Fungal MLST Database at http://mlst.mycologylab.org.

Table II

Nucleotide polymorphic sites and number of plasmid clones sequenced at eight distinct loci of Pneumocystis jirovecii.

\begin{tabular}{|c|c|c|c|c|c|}
\hline \multirow{2}{*}{ Locus } & \multirow{2}{*}{ Genotypes $^{\mathrm{a}}$} & \multirow{2}{*}{ Location $^{\mathrm{b}}$} & \multicolumn{3}{|c|}{ No. of plasmid clones sequenced } \\
\hline & & & SX_0001 & SX_0002 & SX_0003 \\
\hline \multirow[t]{5}{*}{ ITS } & ITS 4 & KC470776 & 0 & 12 & 0 \\
\hline & ITS 10 & JQ365725 & 0 & 0 & 4 \\
\hline & ITS 16 & AB469817 & 0 & 0 & 8 \\
\hline & ITS 22 & KC470795 & 6 & 0 & 0 \\
\hline & ITS 59 & MK300661 & 10 & 0 & 0 \\
\hline \multirow[t]{2}{*}{ sod } & $\operatorname{sod} 1$ & $110 \mathrm{C} / 215 \mathrm{~T}$ & 11 & 13 & 8 \\
\hline & $\operatorname{sod} 2$ & $110 \mathrm{~T} / 215 \mathrm{C}$ & 0 & 0 & 2 \\
\hline dhps & dhps WT & 165A (55Thr) / 171C (57Pro) & 12 & 12 & 12 \\
\hline dhps & dhfr312 & 312C (117Gly) & 12 & 11 & 11 \\
\hline \multirow[t]{4}{*}{$c y b$} & $c y b 1$ & $279 \mathrm{C} / 348 \mathrm{~A} / 516 \mathrm{C} / 547 \mathrm{C} / 566 \mathrm{C} / 838 \mathrm{C}$ & 0 & 0 & 6 \\
\hline & $c y b 2$ & $279 \mathrm{C} / 348 \mathrm{~A} / 516 \mathrm{C} / 547 \mathrm{C} / 566 \mathrm{C} / 838 \mathrm{~T}$ & 0 & 8 & 0 \\
\hline & $c y b 7$ & $279 \mathrm{C} / 348 \mathrm{~A} / 516 \mathrm{C} / 547 \mathrm{C} / 566 \mathrm{~T} / 838 \mathrm{C}$ & 9 & 0 & 0 \\
\hline & $c y b 8$ & $279 \mathrm{~T} / 348 \mathrm{~A} / 516 \mathrm{C} / 547 \mathrm{C} / 566 \mathrm{C} / 838 \mathrm{C}$ & 0 & 0 & 3 \\
\hline \multirow[t]{3}{*}{ mt LSU rRNA } & mt1 & $85 \mathrm{C} / 248 \mathrm{C}$ & 0 & 0 & 2 \\
\hline & $\mathrm{mt} 2$ & $85 \mathrm{~A} / 248 \mathrm{C}$ & 0 & 0 & 8 \\
\hline & $\mathrm{mt} 3$ & $85 \mathrm{~T} / 248 \mathrm{C}$ & 10 & 10 & 0 \\
\hline \multirow[t]{2}{*}{$\beta$-Tub } & $\beta$-Tub 1 & $86 \mathrm{G} / 281 \mathrm{~A}$ & 8 & 0 & 6 \\
\hline & $\beta$-Tub 2 & $86 \mathrm{G} / 281 \mathrm{G}$ & 4 & 12 & 5 \\
\hline \multirow[t]{3}{*}{$26 \mathrm{~S}$ rRNA } & $26 \mathrm{~S} 2$ & $86 \mathrm{~T} / 290 \mathrm{~A}$ & 12 & 11 & 0 \\
\hline & $26 \mathrm{~S} 3$ & $86 \mathrm{C} / 290 \mathrm{~A}$ & 0 & 0 & 5 \\
\hline & $26 \mathrm{~S} 4$ & $86 \mathrm{~A} / 290 \mathrm{~A}$ & 0 & 0 & 6 \\
\hline
\end{tabular}

ITS - internal transcribed spacer regions of rRNA operon, sod - superoxide dismutase, dhfr - dihydrofolate reductase, $d h p$ - dihydropteroate synthase, WT - wild-type, $c y b$ - cytochrome b, $\mathrm{mt}$ - mitochondrial large rRNA subunit, $\beta$-Tub - $\beta$-tubulin, $26 \mathrm{~S}$ rRNA - 26S ribosomal RNA gene

${ }^{a}$ - the genotype nomenclature based on previously published studies and ${ }^{\mathrm{b}}$ - the genotype locations according to the studies previously reported (Walker et al. 1998; Ma et al. 1999; Beard et al. 2000; Denis et al. 2000; Takahashi et al. 2002; Esteves et al. 2010b; Maitte et al. 2013; Xue et al. 2019; Pasic et al. 2020) 


\section{Results}

General information on PCP patients. Clinical information of the patients involved in this study is summarized in Table III. The presence of P. jirovecii in all patients was confirmed by microscopic observation of P. jirovecii cysts in BALF samples stained with GMS (Fig. 1).

Multilocus sequence genotyping. All eight genetic loci P.jirovecii were successfully amplified and sequenced in the BALF specimen from all three patients. Table II shows the polymorphic nucleotide sites, and the number of plasmid clones sequenced for each PCR product from 8 loci. Genotype profiles are summarized in Table IV.

The HIV-negative patient (SX_0003) showed a coinfection with two genotypes of $P$. jirovecii at six of the eight loci sequenced. Of the two HIV-positive patients, one (SX_0001) showed a co-infection with two genotypes of P. jirovecii at two loci, while the other (SX_0002) showed a single infection at all eight loci sequenced.

Of note, the dhps gene (the target of sulfa drugs) in all three P. jirovecii specimens was present as a wildtype sequence. The $d h f r$ gene (the target of trimethoprim) in all three P. jirovecii specimens showed a single synonymous change in the same position (from

Table III

Clinical characteristics of patients with Pneumocystis jirovecii pneumonia.

\begin{tabular}{|c|c|c|c|}
\hline \multirow{2}{*}{ Clinical information } & \multicolumn{3}{|c|}{ Patient No. } \\
\hline & SX_0001 & SX_0002 & SX_0003 \\
\hline Age (years) & 65 & 51 & 65 \\
\hline Sex & Male & Male & Male \\
\hline Underlying conditions & $\mathrm{NA}^{\mathrm{a}}$ & Hepatic cysts & ILD \\
\hline Thoracic HRCT findings & $\mathrm{GGO}^{\mathrm{d}}+$ & GGO + & GGO + \\
\hline HIV $1 / 2$ antibody & $+/-$ & $+/-$ & $-1-$ \\
\hline $\mathrm{CD}_{4}$ T-lymphocyte count (cells/ $\left.\mu \mathrm{l}\right)$ & 232 & 176 & NA \\
\hline \multicolumn{4}{|l|}{ Serum parameters } \\
\hline $1,3-\beta$-D-glucan, normal $<10 \mathrm{pg} / \mathrm{ml}$ & $>600$ & $\mathrm{NA}$ & $>600$ \\
\hline Lactate dehydrogenase, normal 120-250 U/1 & 432 & 699 & 9,734 \\
\hline C-reactive protein, normal 0-6 mg/l & 73.63 & 129.17 & 340.00 \\
\hline Procalcitonin, normal 0-0.05 ng/ml & 0.975 & 0.161 & 11.26 \\
\hline Partial pressure of oxygen, normal $80-110 \mathrm{mmHg}$ & 80 & 65 & 59.70 \\
\hline Erythrocyte sedimentation rate, normal $0-15 \mathrm{~mm} / \mathrm{h}$ & 61.10 & 60.80 & 47.30 \\
\hline Concurrent infection & - & - & C.n. and B.c. ${ }^{b}$ \\
\hline Anti-PCP therapy $^{a}$ & - & - & - \\
\hline HAART before PCP & - & - & - \\
\hline Clinical outcomes & survived & survived & died \\
\hline
\end{tabular}

NA - not available; ILD - interstitial lung disease; HRCT - high-resolution computed tomography;

GGO - ground-glass opacity; HIV - human immunodeficiency virus;

HAART - highly active antiretroviral therapy

+- positive, - - negative

a - Anti-PCP therapy, TMP-SMZ prophylaxis for P. jirovecii pneumonia

b - Candida norvegensis and Burkholderia cepacia

Table IV

Genotypes of Pneumocystis jirovecii detected at eight genetic loci.

\begin{tabular}{|c|c|c|c|c|c|c|c|c|c|}
\hline \multirow{2}{*}{$\begin{array}{c}\text { Patient } \\
\text { No. }\end{array}$} & \multirow{2}{*}{$\begin{array}{c}\text { HIV1/2 } \\
\text { anti- } \\
\text { body }\end{array}$} & \multicolumn{8}{|c|}{ Genotypes at 8 loci } \\
\hline & & ITS & sod & $d h f r$ & $d h p s$ & $c y b$ & mtLSU rRNA & $\beta$-Tub & 26S rRNA \\
\hline SX_0001 & $+1-$ & ITS2 + ITS59 & sod1 & dhfr312 & $W T$ & $c y b 7$ & $\mathrm{mt} 3$ & $\beta-$ Tub1 $+\beta-$ Tub2 & $26 \mathrm{~S} 2$ \\
\hline SX_0002 & $+1-$ & ITS4 & sod1 & dhfr 312 & $W T$ & $c y b 2$ & $\mathrm{mt} 3$ & $\beta$-Tub2 & $26 \mathrm{~S} 2$ \\
\hline SX_0003 & $-1-$ & ITS10+ ITS16 & $\operatorname{sod} 1+\operatorname{sod} 2$ & dhfr312 & $W T$ & $c y b 1+c y b 8$ & $\mathrm{mt} 1+\mathrm{mt} 2$ & $\beta$-Tub1 $+\beta-$ Tub2 & $26 \mathrm{~S} 3+26 \mathrm{~S} 4$ \\
\hline
\end{tabular}

ITS - internal transcribed spacer regions of rRNA operon, sod - superoxide dismutase, $d h f r$ - dihydrofolate reductase, $d h p s$ - dihydropteroate synthase, WT - wild-type, $c y b$ - cytochrome b, mt - mitochondrial large rRNA subunit, $\beta$-Tub - $\beta$-tubulin, 26S rRNA - 26S rRNA gene 
Fig. 1. Identification of Pneumocystis jirovecii using GMS staining methods. Cysts appear as brown or puce spheres or ovoids with a small black stick inside (arrows).

The reddish background instead of the typical greenish background is most likely due to periodic acid treatment and without light green counterstaining in our staining method.

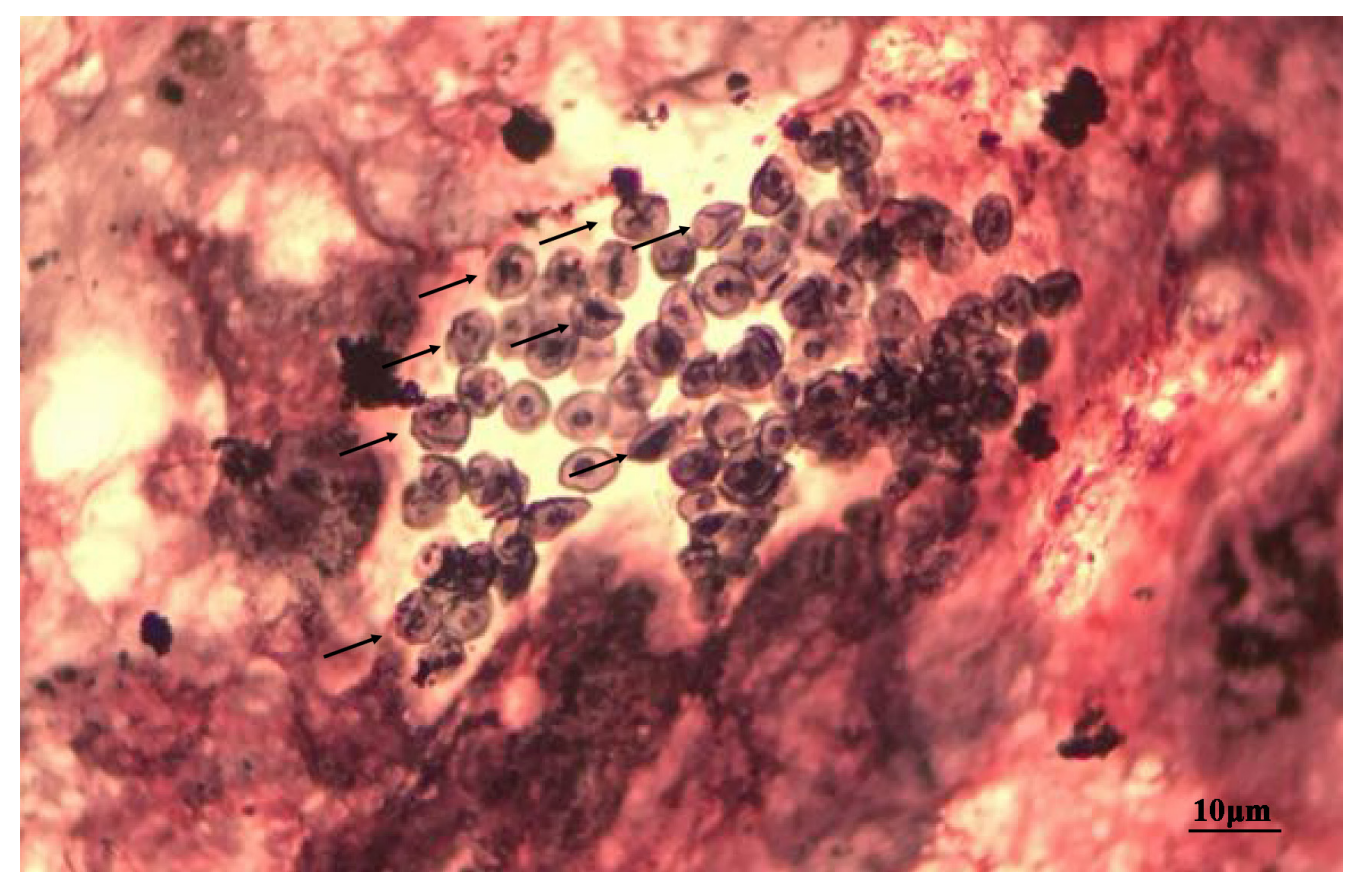

$\mathrm{T}$ to $\mathrm{C}$ at nucleotide 312 ). The $c y b$ gene (the target of atovaquone) in the three $P$. jirovecii specimens showed polymorphisms in three nucleotide positions (at 279, 566 and 838), resulting in 4 genotypes including $c y b 1$, $c y b 2, c y b 7$ and $c y b 8$ based on the nomenclature system described by Esteves and Maitte (Esteves et al. 2010b; Maitte et al. 2013). Genotypes cyb 2 and $c y b 7$ were presented only in patients SX_0002 and SX_0001, respectively, while genotypes $c y b 1$ and $c y b 8$ were present as a mixture in the patient SX_003. Of the three polymorphisms, one is synonymous (at 279 in genotype $c y b 8$ ) and the other two are nonsynonymous (at 566 in genotype $c y b 7$ and 838 in genotype $c y b 2$ ).

Due to the presence of coinfection with two genotypes at 2 or 6 loci in two of the three patients (SX_0001 and SX_0003), we could not determine the exact MLST types in either patient (Table V).

\section{Discussion}

Despite having been recognized as an important human pathogen for many years, strain variation of $P$. jirovecii remains poorly understood due largely to the absence of a reliable in vitro culture system. To date, $P$. jirovecii strain typing has relied primarily on analyzing genetic markers after PCR amplification. While there have been about a dozen genetic markers reported (Ma et al. 2018), most studies have used only a small number of genetic markers in epidemiological investigations, potentially limiting the discriminatory power for strain differentiation. In this study, we performed strain typing of $P$. jirovecii using a total of eight genetic markers, including six nuclear genes (ITS, 26S rRNA,
Table V

Multi-locus sequence type (MLST) profiles of P.jirovecii from PCP patients in this study in comparison with known $P$. jirovecii MLST profiles in Fungal MLST Database.

\begin{tabular}{|c|c|c|c|c|c|}
\hline $\begin{array}{l}\text { MLST } \\
\text { types }\end{array}$ & $\beta$-Tub & $c y b$ & 26S rRNA & sod & $\begin{array}{c}\text { Patient } \\
\text { no. }\end{array}$ \\
\hline 3 & 1 & 1 & 4 & 2 & SX_0003 \\
\hline 8 & 2 & 8 & 4 & 1 & SX_0003 \\
\hline 13 & 1 & 1 & 4 & 1 & SX_0003 \\
\hline 15 & 1 & 8 & 4 & 1 & SX_0003 \\
\hline 19 & 1 & 8 & 3 & 2 & SX_0003 \\
\hline 21 & 2 & 1 & 3 & 1 & SX_0003 \\
\hline 22 & 2 & 1 & 3 & 2 & SX_0003 \\
\hline 23 & 2 & 1 & 4 & 1 & SX_0003 \\
\hline 35 & 2 & 7 & 2 & 1 & SX_0001 \\
\hline 51 & 1 & 7 & 2 & 1 & SX_0001 \\
\hline 52 & 2 & 2 & 2 & 1 & SX_0002 \\
\hline NA & 1 & 1 & 3 & 2 & SX_0003 \\
\hline NA & 2 & 8 & 3 & 1 & SX_0003 \\
\hline NA & 2 & 8 & 3 & 2 & SX_0003 \\
\hline NA & 2 & 1 & 4 & 2 & SX_0003 \\
\hline NA & 2 & 8 & 4 & 2 & SX_0003 \\
\hline NA & 1 & 1 & 3 & 1 & SX_0003 \\
\hline NA & 1 & 8 & 3 & 1 & SX_0003 \\
\hline NA & 1 & 8 & 4 & 2 & SX_0003 \\
\hline
\end{tabular}

* - The first 11 MLST types (numbered 3 to 52) identified in this study correspond to those in the Fungal MLST Database at http://mlst.mycologylab.org

NA - types identified in this study and not available from the Fungal MLST Database

In both patients SX_0001 and SX_0003 (with co-infection of two genotypes at 2 or 6 loci, respectively), there were a total of four and 64 potential MLST profiles, respectively. Only two and 16 of those profiles are listed in this table while the true profiles could not be determined in this study. 
sod, dhps, dhfr and $\beta$-Tub) and two mitochondrial genes (mtLSU-rRNA and $c y b$ ).

While only three clinical specimens were examined including two from HIV-infected patients and one from a non-HIV patient, we identified complex genotype profiles (Table II). Multiple unique genotypes (from 2 to 5) were identified at all these eight loci except for two (dhps and $d h f r$ ), which showed a single genotype. Two of three clinical specimens showed a mixture of multiple genotypes at two or six loci, suggesting a coinfection with multiple $P$. jirovecii strains, without any strains shared between the three patients. This represents the first report of genetic polymorphisms in PCP patients in Shanxi Province, China. Our findings expand our understanding of the genetic diversity of $P$. jirovecii in China.

The ITS locus involved in this study includes ITS1 and ITS2, and 5.8S rRNA of the nuclear rRNA operon was amplified in one fragment of approximately $490 \mathrm{bp}$ and is also known as ITS1-5.8S-ITS2 (Xue et al. 2019). Sequence analysis of this locus in this study identified five unique genotypes (nos. $4,10,16,22$, and 59) based on the genotype nomenclature system in our earlier report (Xue et al. 2019), which is more than genotypes identified from all other seven loci examined. This is consistent with many previous studies showing this locus to be the most polymorphic genetic marker for P. jirovecii genotyping (Ma et al. 2018). All ITS genotypes identified in this study have also been reported from previous studies conducted by our group (Xue et al. 2019) and others in China (Li et al. 2013; Sun et al. 2015) as well as studies from other countries (Atzori et al. 1998; Miller and Wakefield 1999; Matsumura et al. 2011).

In this study, we examined genetic polymorphisms of three drug target genes, including $d h f r$, dhps and $c y b$, which are the targets of trimethoprim, sulfa, and atovaquone drugs, respectively. No nonsynonymous mutation was found at $d h f r$ or $d h p s$ in any specimens in this study, while a single synonymous change in the same position at $d h f r$ (from $\mathrm{T}$ to $\mathrm{C}$ at nucleotide 312 ) was present in all three specimens. This change has been reported in previous studies from China (Deng et al. 2014; Wang et al. 2019) and other countries (Esteves et al. 2010b; Muñoz et al. 2012; Suárez et al. 2017; Singh et al. 2019). As for the $c y b$ gene, we identified nucleotide changes at three positions (at 279, 566 and 838), which gave rise to 4 unique genotypes ( $c y b 1$, $c y b 2, c y b 7$ and $c y b 8$ ). All these genotypes have also been reported from China (Deng et al. 2016; Wang et al. 2019) and other countries (Esteves et al. 2010b; Maitte et al. 2013; Sokulska et al. 2018; Szydlowicz et al. 2019; Le Gal et al. 2020; Goterris et al. 2022). The nucleotide changes at two positions (566 and 838) are synonymous (S189L and L180F) but do not correspond to any of the seven mutations that are suggested to be associated with atovaquone resistance in previous studies (Kessl et al. 2004). The absence of mutations in all these three drug targets potentially associated with resistance is consistent with no known use of the respective drugs in the history of the patients.

The major limitation of this study is the small sample size, which precludes the generalization of the results to a larger population and the assessment of correlation of genotypes with clinical characteristics and treatment outcomes. Further studies are required using more samples from different patient populations.

\section{Conclusions}

In conclusion, we assessed and analyzed the genetic polymorphisms of $P$. jirovecii genotypes at eight loci and identified complex genotype profiles, including the presence of coinfection with up to 5 genotypes at six loci. This is the first report of genetic polymorphisms in PCP patients in Shanxi Province, China. Our findings expand our understanding of the genetic diversity of P. jirovecii in China. However, a large-scale collection of clinical isolates of $P$. jirovecii from different patient populations is required for more detailed studies and the correlation of genotypes with clinical characteristics and outcomes.

\section{Acknowledgments}

This work was supported by the Basic Research Projects of Natural Sciences in Shanxi Province (No. 20210302124039), the Scientific and Technological Innovation Programs of Higher Education Institutions in Shanxi (STIP: No. 2020L0201), the Start-up Foundation for Doctoral Scientific Research of Shanxi Medical University (No.XD1905), the Start-up Foundation for Doctoral Scientific Research of Shanxi province (No. SD1905), and Natural Science Foundation of LiaoningProvince (No. LJKZ0796). We thank the staff members at the Shanxi Key Laboratory of Carcinogenesis and Translational Research on Esophageal Cancer for their assistance.

\section{Conflict of interest}

The authors do not report any financial or personal connections with other persons or organizations, which might negatively affect the contents of this publication and/or claim authorship rights to this publication.

\section{Literature}

Atzori C, Angeli E, Agostoni F, Mainini A, Micheli V, Cargnel A. Biomolecular techniques to detect Pneumocystis carinii f. sp. hominis pneumonia in patients with acquired immunodeficiency syndrome. Int J Infect Dis. 1998;3(2):76-81.

https://doi.org/10.1016/s1201-9712(99)90013-9

Beard CB, Carter JL, Keely SP, Huang L, Pieniazek NJ, Moura IN,

Roberts JM, Hightower AW, Bens MS, Freeman AR, et al. Genetic 
variation in Pneumocystis carinii isolates from different geographic regions: implications for transmission. Emerg Infect Dis. 2000;6(3): 265-272. https://doi.org/10.3201/eid0603.000306

Cañas-Arboleda A, Hernández-Flórez C, Garzón J, ParraGiraldo CM, Burbano JF, Cita-Pardo JE. Colonization by Pneumocystis jirovecii in patients with chronic obstructive pulmonary disease: association with exacerbations and lung function status. Braz J Infect Dis. 2019;23(5):352-357.

https://doi.org/10.1016/j.bjid.2019.08.008

Deng X, Xiong M, Lan Y, Zhuo L, Chen W, Tang X. [The gene polymorphisms of drug targets in Pneumocystis jirovecii isolates] (in Chinese). Chin J Infect Dis. 2016;34(7):395-399.

https://doi.org/10.3760/cma.j.issn.1000-6680.2016.07.002

Deng X, Zhuo L, Lan Y, Dai Z, Chen WS, Cai W, Kovacs JA, Ma L, Tang X. Mutational analysis of Pneumocystis jirovecii dihydropteroate synthase and dihydrofolate reductase genes in HIV-infected patients in China. J Clin Microbiol. 2014;52(11):4017-4019.

https://doi.org/10.1128/JCM.01848-14

Denis CM, Mazars E, Guyot K, Odberg-Ferragut C, Viscogliosi E, Dei-Cas E, Wakefield AE. Genetic divergence at the SODA locus of six different formae speciales of Pneumocystis carinii. Med Mycol 2000;38(4):289-300.

https://doi.org/10.1080/mmy.38.4.289.300

Esteves F, Gaspar J, Marques T, Leite R, Antunes F, Mansinho K Matos O. Identification of relevant single-nucleotide polymorphisms in Pneumocystis jirovecii: relationship with clinical data. Clin Microbiol Infect. 2010a;16(7):878-884

https://doi.org/10.1111/j.1469-0691.2009.03030.x

Esteves F, Gaspar J, Tavares A, Moser I, Antunes F, Mansinho K, Matos O. Population structure of Pneumocystis jirovecii isolated from immunodeficiency virus-positive patients. Infect Genet Evol. 2010b;10(2):192-199.

https://doi.org/10.1016/j.meegid.2009.12.007

Goterris L, Pasic L, Murillo MG, Kan A, Anton A, Company JA, Ruiz-Camps I, Meyer W, Martin-Gomez MT. Pneumocystis jirovecii genetic diversity in a Spanish tertiary hospital. Med Mycol. 2022; 60(1):myab065. https://doi.org/10.1093/mmy/myab065

Kessl JJ, Hill P, Lange BB, Meshnick SR, Meunier B, Trumpower BL. Molecular basis for atovaquone resistance in Pneumocystis jirovecii modeled in the cytochrome bc(1) complex of Saccharomyces cerevisiae. J Biol Chem. 2004;279(4):2817-2824.

https://doi.org/10.1074/jbc.M309984200

Lane BR, Ast JC, Hossler PA, Mindell DP, Bartlett MS, Smith JW, Meshnick SR. Dihydropteroate synthase polymorphisms in Pneumocystis carinii. J Infect Dis. 1997;175(2):482-485.

https://doi.org/10.1093/infdis/175.2.482

Le Gal S, Hoarau G, Bertolotti A, Negri S, Le Nan N, Bouchara JP, Papon N, Blanchet D, Demar M, Nevez G. Pneumocystis jirovecii diversity in Réunion, an overseas French Island in Indian Ocean. Front Microbiol. 2020;11:127.

https://doi.org/10.3389/fmicb.2020.00127

Lee CH, Helweg-Larsen J, Tang X, Jin S, Li B, Bartlett MS, Lu JJ, Lundgren B, Lundgren JD, Olsson M, et al. Update on Pneumocystis carinii f. sp. hominis typing based on nucleotide sequence variations in internal transcribed spacer regions of rRNA genes. J Clin Microbiol. 1998;36(3):734-741.

https://doi.org/10.1128/JCM.36.3.734-741.1998

Li K, He A, Cai WP, Tang XP, Zheng XY, Li ZY, Zhan XM. Genotyping of Pneumocystis jirovecii isolates from Chinese HIV-infected patients based on nucleotide sequence variations in the internal transcribed spacer regions of rRNA genes. Med Mycol. 2013; 51(1):108-112.

https://doi.org/10.3109/13693786.2012.695458

Ma L, Borio L, Masur H, Kovacs JA. Pneumocystis carinii dihydropteroate synthase but not dihydrofolate reductase gene mutations correlate with prior trimethoprim-sulfamethoxazole or dapsone use. J Infect Dis. 1999;180(6):1969-1978. https://doi.org/10.1086/315148 Ma L, Cisse $\mathbf{O H}$, Kovacs JA. A molecular window into the biology and epidemiology of Pneumocystis spp. Clin Microbiol Rev. 201813;31(3):e00009-18.

https://doi.org/10.1128/CMR.00009-18

Maitte C, Leterrier M, Le Pape P, Miegeville M, Morio F. Multilocus sequence typing of Pneumocystis jirovecii from clinical samples: how many and which loci should be used? J Clin Microbiol. 2013;51(9):2843-2849.

https://doi.org/10.1128/JCM.01073-13

Matsumura Y, Shindo Y, Iinuma Y, Yamamoto M, Shirano M, Matsushima A, Nagao M, Ito Y, Takakura S, Hasegawa Y, et al. Clinical characteristics of Pneumocystis pneumonia in non-HIV patients and prognostic factors including microbiological genotypes. BMC Infect Dis. 2011;11:76

https://doi.org/10.1186/1471-2334-11-76

Miller RF, Wakefield AE. Pneumocystis carinii genotypes and severity of pneumonia. Lancet. 1999;353(9169):2039-2040.

https://doi.org/10.1016/S0140-6736(99)01690-6

Muñoz C, Zuluaga A, Restrepo A, Tobon A, Cano LE, Gonzalez A. Molecular diagnosis and detection of Pneumocystis jirovecii DHPS and DHFR genotypes in respiratory specimens from Colombian patients. Diagn Microbiol Infect Dis. 2012;72(3):204-213.

https://doi.org/10.1016/j.diagmicrobio.2011.11.015

Pasic L, Goterris L, Guerrero-Murillo M, Irinyi L, Kan A, Ponce CA, Vargas SL, Martin-Gomez MT, Meyer W. Consensus multilocus sequence typing scheme for Pneumocystis jirovecii. J Fungi (Basel). 2020;6(4):259. https://doi.org/10.3390/jof6040259 Singh Y, Mirdha BR, Guleria R, Kabra SK, Mohan A, Chaudhry R, Kumar L, Dwivedi SN, Agarwal SK. Genetic polymorphisms associated with treatment failure and mortality in pediatric Pneumocystosis. Sci Rep. 2019;9(1):1192.

https://doi.org/10.1038/s41598-018-38052-x

Sokulska M, Kicia M, Wesolowska M, Piesiak P, Kowal A, Lobo ML, Kopacz Z, Hendrich AB, Matos O. Genotyping of Pneumocystis jirovecii in colonized patients with various pulmonary diseases. Med Mycol. 2018;56(7):809-815.

https://doi.org/10.1093/mmy/myx121

Suárez I, Roderus L, van Gumpel E, Jung N, Lehmann C, Fätkenheuer G, Hartmann P, Plum G, Rybniker J. Low prevalence of DHFR and DHPS mutations in Pneumocystis jirovecii strains obtained from a German cohort. Infection. 2017;45(3):341-347. https://doi.org/10.1007/s15010-017-1005-4

Sun L, Huang M, Wang J, Xue F, Hong C, Guo Z, Gu J. Genotyping of Pneumocystis jirovecii isolates from human immunodeficiency virus-negative patients in China. Infect Genet Evol. 2015;31:209-215. https://doi.org/10.1016/j.meegid.2015.01.021

Szydlowicz M, Jakuszko K, Szymczak A, Piesiak P, Kowal A, Kopacz Z, Wesolowska M, Lobo ML, Matos O, Hendrich AB, et al. Prevalence and genotyping of Pneumocystis jirovecii in renal transplant recipients-preliminary report. Parasitol Res. 2019;118(1):181-189. https://doi.org/10.1007/s00436-018-6131-0

Takahashi T, Endo T, Nakamura T, Sakashita H, Kimura K, Ohnishi K, Kitamura Y, Iwamoto A. Dihydrofolate reductase gene polymorphisms in Pneumocystis carinii f. sp. hominis in Japan. J Med Microbiol. 2002;51(6):510-515.

https://doi.org/10.1099/0022-1317-51-6-510

Wakefield AE. DNA sequences identical to Pneumocystis carinii f. sp. carinii and Pneumocystis carinii f. sp. hominis in samples of air spora. J Clin Microbiol. 1996;34(7):1754-1759.

https://doi.org/10.1128/JCM.34.7.1754-1759.1996

Walker DJ, Wakefield AE, Dohn MN, Miller RF, Baughman RP, Hossler PA, Bartlett MS, Smith JW, Kazanjian P, Meshnick SR. Sequence polymorphisms in the Pneumocystis carinii cytochrome b 
gene and their association with atovaquone prophylaxis failure. J Infect Dis. 1998;178(6):1767-1775. https://doi.org/10.1086/314509 Wang DD, Zheng MQ, Zhang N, An CL. Investigation of Pneumocystis jirovecii colonization in patients with chronic pulmonary diseases in the People's Republic of China. Int J Chron Obstruct Pulmon Dis. 2015;10:2079-2085. https://doi.org/10.2147/COPD.S89666 Wang M, Xu X, Guo Y, Tao R, Hu C, Dong X, Huang Y, Zhu B. Polymorphisms involving the Pneumocystis jirovecii-related genes in AIDS patients in eastern China. Infect Genet Evol. 2019;75:103955. https://doi.org/10.1016/j.meegid.2019.103955
Xue T, Ma Z, Liu F, Du W, He L, Wang J, An C. Pneumocystis jirovecii colonization and its association with pulmonary diseases: a multicenter study based on a modified loop-mediated isothermal amplification assay. BMC Pulm Med. 2020;20(1):70.

https://doi.org/10.1186/s12890-020-1111-4

Xue T, Ma Z, Liu F, Du WQ, He L, Ma L, An CL. Genotyping of Pneumocystis jirovecii by use of a new simplified nomenclature system based on the internal transcribed spacer regions and 5.8S rRNA gene of the rRNA operon. Clin Microbiol. 2019;57(6):e02012-18. https://doi.org/10.1128/JCM.02012-18 